Marisa González de Oleaga,

Itinerarios. Historiografía y posmodernidad,

Madrid, Postmetrópolis Editorial, 2019, 271 páginas

La aventura historiográfica iniciada por Marisa González de Oleaga en este texto es, a todas luces, un significativo aporte a un campo escasamente transitado por los especialistas latinoamericanos y españoles. La autora plantea su texto como un manifiesto, un camino de incierta traza o, mejor aun, "una experiencia de lectura", más que como un estado de la cuestión o un ejercicio erudito sobre determinadas polémicas historiográficas. Frente a la elección de relatos que se puedan encasillar y rotular claramente, este es un recorrido por productos híbridos construido sobre los aportes anglosajones en relación al debate de la posmodernidad (o lo posmoderno), poco conocido o directamente vilipendiado quizá por desconocimiento en América Latina. Un ejemplo se puede encontrar en la extensa obra de Julio Aróstegui de amplia circulación como manual y guía metodológica entre hispanohablantes, que menciona el influjo del posmodernismo frente a la crisis de la historia en el anticientificismo, una retórica del discurso frente a la estructura social, el deconstruccionismo frente al contextualismo, el ficcionalismo y orientaciones que, a fines del siglo xx, habían ido virando a la reconstrucción literaria del pasado, la interpretación semiótica, la exploración micro- antropológica. En general, las posturas relativistas rechazaban según esta visión las anteriores pretensiones de encontrar explicaciones teóricas generales en el estudio de la historia. ${ }^{1}$

\section{González de Oleaga}

demuestra similares

preocupaciones a las que expone en Itinerarios en su prólogo de la versión en español de Rethinking History, de Keith Jenkins (publicado en 1990 en inglés). Este libro es una suerte de guía, un trabajo provocador que analiza los presupuestos epistemológicos de la historia. Jenkins, lejos de conducir a la autodisolución del conocimiento, entablaba con los lectores un diálogo no carente de humor en el medio de una crisis, aunada al significado profundo de su práctica. Este autor indicaba que un abismo ontológico entre pasado e historia, que separa la naturaleza de las cosas, implica que no es posible realmente a través de una metodología específica conocer el pasado; los métodos históricos constituyen una serie de rigurosas técnicas, habilidades, conceptos y rutinas que conducen a la objetividad, pero esos conceptos claves con los cuales se trabaja son construcciones recientes, y parciales. En resumen, la

\footnotetext{
${ }^{1}$ Julio Aróstegui, La investigación histórica. Teoría y método, Barcelona, Crítica, 2001.
}

historia es un campo de batalla donde se construyen interpretaciones del pasado de manera ideológica. El texto de Jenkins tardó casi veinte años en publicarse en español, situación que permite entender en parte las dificultades y las controversias disciplinares y la extensión o no del debate en tierras no anglosajonas. ${ }^{2}$

González de Oleaga registra en Itinerarios aportes académicos relevantes en diferentes sustratos y disciplinas: filosofía, antropología, lingüística y, por supuesto, historia. En principio, el texto denota una advertencia sobre, justamente, una preocupación a tono con las críticas al posmodernismo: el relativismo del "todo vale". En la introducción, se alerta en relación a la riqueza de las interpretaciones que abrió la crisis historiográfica de fines del siglo $\mathrm{xx}, \mathrm{y}$, sobre todo, respecto a la importancia de advertir la dimensión performativa del lenguaje.

Itinerarios aloja varias respuestas y a la vez interrogantes a las nociones generales sobre la objetividad racional del discurso histórico, las formas expositivas y los límites del lenguaje y, en general, a las críticas sobre el relativismo y el nihilismo posmoderno. Relataremos

\footnotetext{
${ }^{2}$ Keith Jenkins, Repensar la historia, Madrid, Siglo XXI, 2009, p. 25.
} 
algunos de estos caminos, ya que es imposible abordarlos todos en su enorme complejidad interpretativa. Pondremos el eje en determinados debates que la autora, con paciencia y denodada maestría, reconstruye a la luz de discusiones actuales.

La reflexión está encabezada por la frase "There is no King in Israel", cita de la obra clásica de Peter Novick That Noble Dream. The Objetivity Question. ${ }^{3}$ Funciona como metáfora de la libertad de pensamiento epistemológico por sobre la de la seguridad que otorgaban los paradigmas explicativos teóricos propios del estructuralismo. Al mismo tiempo, González de Oleaga indica cómo a mayor autonomía teórica, encontramos mayor responsabilidad, dado que este abandono de líneas determinadas implica, con sus límites y sus promesas, un recorrido solitario y no ya la posibilidad de una validación teórica de determinadas escuelas.

En este sentido, el texto hace suyo el debate sobre la posmodernidad, plagado ciertamente de malos entendidos. ${ }^{4} \mathrm{Y}$ lo hace ubicándose en un registro que, lejos de ser expositivo, persuade con múltiples (y acertadas) metáforas, donde se dibujan las dificultades teóricas

${ }^{3}$ Peter Novick, That Noble Dream. The 'Objectivity Question' and the American Historical Profession, Cambridge, Cambridge University Press, 1988.

${ }^{4}$ Joyce Appleby, Lynn Hunt y Margaret Jacob, "El posmodernismo y la crisis de la modernidad", en L. G. Morales Moreno (comp.), Historia de la historiografía contemporánea (de 1968 a nuestros días), México, Instituto Mora, 2005, pp. 108-148. del lenguaje y de la historia. Por ejemplo, en diálogos imaginarios entre historiadores e historiadoras se desenvuelven las críticas más elaboradas a la posmodernidad. En esa elección se permite un dinamismo y apertura que no es posible clausurar con una definición o resultado estático. Así, las conversaciones entre Geoffrey Elton, Cristopher Norris, Lawrence Stone, Gabrielle Spiegel, Norman Stone, Terry Eagleton y Gertrude

Himmelfarb proporcionan el andamiaje para entrever las renuencias a las nociones "relativistas".

González de Oleaga sintetiza de manera original tales detracciones y críticas, a veces virulentas. En primer lugar, la historiografía bajo el giro lingüístico neutralizaría esa supuesta "función social" de la historia. Es decir, las explicaciones sobre la transmisión de los logros culturales de la humanidad, el funcionamiento de la sociedad y el análisis de sus transformaciones. Al negársele o carecer de la certeza en esos campos tan sensibles, la investigación también desestabilizaría la utilidad del conocimiento histórico, con lo cual el debate epistémico se transforma en uno sobre la ideología y el poder. En segundo lugar, las críticas a la posmodernidad con su antirrealismo llevan implícita una sospecha: la falta de profesionalismo y una defensa corporativa hacia aquellos dispuestos a "salir" del escenario demarcado. Los "rebeldes", como Patrick Joyce, Catriona Kelly o Wulf Kansteiner, pueden también ser acusados de forzar una ruptura epistémica para hacerse de un espacio académico en un medio sobrepoblado y altamente competitivo.

González de Oleaga elige revisar el aparentemente confuso espacio posmoderno pero no para gestar un "estado de la cuestión" propositivo, sino una narración polifónica. En ella, las formas tienen tanto que ver con el fondo: son ilegibles e imposibles de visualizar uno sin las otras. La autora alerta sobre la importancia de "modos y maneras" literarias, es decir, sobre la importancia de una escritura no exclusivamente técnica con sentido expositivo. Se alude a la significación profunda de la "forma" del texto y tal cuestión es claramente un guiño para que la búsqueda del rigor y la erudición no encuentre en el achatamiento propio de una supuesta objetividad narrativa el "rigor mortis".

A los debates sobre el contenido de la forma de la narración se unen otros interrogantes sobre la evidencia, es decir, la prueba de la existencia de una realidad. Para muchos de los detractores de la posmodernidad, esa sustancia está en el pasado y depende por lo tanto de su "descubrimiento"; pero no asume la posibilidad de que esa especie elusiva y esencial pueda ser lo no dicho, la negación. González de Oleaga destaca una metáfora de Frank Ankersmist, uno de los más conspicuos posmodernos, para definir ambas posturas gnoseológicas: para los partidarios de la ciencia moderna, la evidencia es una baldosa que, al levantarla, les permitirá conocer; para los 
posmodernos, sin embargo, no significa más que el sitio desde donde moverse hacia otras. En resumen, si se pudieran definir esas diferencias, el primer ejercicio sería vertical, mientras que las lógicas posmodernas apuntan hacia una constante búsqueda horizontal, ciertamente más difícil de encasillar y encerrar, pero no por ello acientífica.

Itinerarios permite así entrever los aspectos nodales del alcance indeterminado y elusivo de las llamadas teorías posmodernas (que a su vez la autora define como inexistentes en tanto que conjunto). Y, mucho más, permite comprender las posibilidades abiertas para hibridar tradiciones y pensar sobre las prácticas más allá de los paradigmas centrados en el documento y su lectura. Historiadores e historiadoras se han cuestionado ya de manera contundente que a través de un lenguaje se refleja la realidad y se administra el acceso a una verdad histórica. Si bien esa ficción no se puede mantener, es difícil encontrar asidero en la inestabilidad que, según sus críticos, inaugura la versión contrapuesta y posmoderna de la historia. González de Oleaga apuesta por "una imperiosa demanda de deseo frente a la tiranía de la norma". Enemiga de clausurar y de etiquetar, propone, presenta y argumenta sin prescribir un "querer ser" errático frente a un "deber ser social, político y cultural". En la apertura de estas opciones, el libro admite honestamente la imposibilidad de condensar todos los aportes sucedidos a través de varias décadas. Pero, sin duda, demarca un derrotero en estos apasionados debates que sobresalen de la historia y se desplazan hacia nuestra forma de conocer también en el presente.

\author{
María Silvia Di Liscia \\ IEHSOLP-Universidad \\ Nacional de La Pampa / \\ CONICET
}

